\title{
IMPROVEMENT OF HYDROELECTRIC POWER GENERATION USING PUMPED STORAGE SYSTEM
}

\author{
0. O. E. Ajibola1, ${ }^{1}$, O. S. Ajala², J. 0. Akanmu ${ }^{3}$ and 0. J. Balogun ${ }^{4}$ \\ 1, 4 DEPARTMENT OF SYSTEMS ENGINEERING, UNIVERSITY OF LAGOS, AKOKA, YABA, LAGOS, LAGOS STATE. NIGERIA

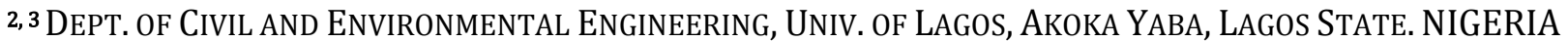 \\ E-mail addresses:1oajibola@unilag.edu.ng,2tommie_mide@yahoo.com,3 jakanmu@unilag.edu.ng, \\ 4 seyi8030@yahoo.com
}

\begin{abstract}
Hydroelectric power is a renewable source of energy. By principle, hydroelectric power generation relies on the law of conservation of energy where kinetic energy that resulted from the movement of the mass of water from the river is translated into electricity, the quantum of which depends on systemic variables viz: plant efficiency, volumetric water flow through the turbine and the head of the water from the water surface to the turbine. Understanding the dynamics of these variables, and the correlation between them are core to proper planning and management of a hydroelectric power station. In this Study, simple mathematical methods that include linear programming and statistical analysis based on simulation techniques were used to evaluate vital parameters based on the data obtained from the Hydrologic units of the Shiroro Power Stations in Nigeria. The overall aim of the study is to idealize power generation at Shiroro dam in and out of raining season so as to ensure optimum generation of electricity all year round in order to achieve energy sufficiency in Nigeria. The result of the study is encouraging as it supports the viability of the pumped storage system for generating hydroelectric power all year round. The coupling of the hydroelectric power with pumped storage system if properly harnessed could be the needed panacea for the erratic power supply in Nigeria.
\end{abstract}

Keywords: hydroelectric power, pumped storage, reservoir inflows, turbine, hydrological variables, simulation techniques.

\section{INTRODUCTION}

In Nigeria, a major factor that has reduced the standard of living of an average Nigerian to near zero is the epileptic supply of power. The effect of epileptic supply of power in Nigeria is conspicuous in the manufacturing sector where $90 \%$ of factories are moribund. The sporadic supply of power in Nigeria affects every sphere of human endeavour. These catastrophic effects range from all forms of domestic discomfort to national embarrassment. For instance there was a three hour power outage at the Muritala Mohammed International Airport in Ikeja, Lagos on Sunday the $9^{\text {th }}$ day of May, 2010 and the ugly incidence was repeated on Tuesday the 11th of May of the same year. Power supply situation in Nigeria has no doubt affected the economy of the nation negatively in no small measure.

Basically, the power generated at a hydroelectric power plant results from the kinetic energy that produced the torque obtained from the mass of water that falls through the height, $\mathrm{h}$; the differential of head of water from the inlet point $H_{1}$, and the head of water above the turbine $\mathrm{H}_{2}$. Hence $h=H_{1}-H_{2}$. The process of conversion involves a hydraulic turbine which converts the kinetic energy of the flowing water into mechanical work that produce a torque. A dynamo then converts the torque thus produced into electricity [1]. The operation of a generator is based on Faraday's principle of electromagnetism. Faraday propounded that when a magnet is moved past a conductor, it causes electricity to flow in the conductor. In a large generator, electromagnets are made by circulating direct current through loops of wire wound around stacks of magnetic steel laminations. These are called field poles, and are mounted on the perimeter of the rotor. The rotor is attached to the turbine shaft, which rotates at a fixed speed. When the rotor turns, it causes the field poles (the electromagnets) to move past the 
conductors mounted in the stator that causes electricity to flow and develop potential difference across the generator output terminals [2]. Hydroelectric power generation thus produced is computed from the mass of water that flows through the Turbine based on the release from the reservoir and constrained by the Turbines flow capacity [3]. The volume of water that passes through the Turbines is bounded by maximum and minimum Turbine flow. If there is too much water, excess water is released through spillways which do not contribute to the generation of electricity. If however the release is less than the minimum Turbine flow then no electricity is generated. Therefore the amount of electricity that can be generated at a hydroelectric plant is dependent upon two factors, [4]. These factors are:

(1) The vertical distance through which the water falls usually refers to as the Head and

(2) The rate of flow of water $\left(\mathrm{m}^{3} \mathrm{~s}^{-1}\right)$.

Thus the quantity of electricity produced is proportional to the product of the head and the rate of the flow. Accurate quantification of the reservoir content and adequate knowledge of reservoir operating policies is paramount to ensure optimal storage of water in the reservoir when managing production of hydroelectric energy. Climatic conditions affect both the availability and reliability of the water stored in reservoirs. To this end, optimum management of such reservoirs is very important under different climatic uncertainties, $[5,6]$.

\subsection{Theoretical Considerations}

This section contains an elucidatory consideration of the theories and guiding policies upon which the systematic build-up of the models and solution contained therein are based. System dynamics (SD) is a method for understanding the dynamic behaviour of complex systems, [7]. The SD procedure includes: defining and identifying a problem, analyzing the problem, identifying possible solution, developing an algorithm, selecting the best solution, evaluating the solution and implementing this solution

Some of the characteristics of SD methodology which makes it suitable for this work include:

i. Understanding the problem situation: The purpose is to clearly identify the problem and its causative factors as well as the relationships between them;

ii. Explicit conceptual model and simulation model building: a sign causal diagram is drawn in order to develop the understanding of influence of the variables on each other. Explicit concepts of SD such as flows, levels and auxiliary are used in simulation model building process;

iii. Simulation and gathering the results: after building the simulation model, it is then possible to analyze different scenarios for different policies

An over view of a hydro-electric power plant in Figure 1, indicates that:

(i) Hydro-electricity generators converts the kinetic energy of the falling water into electrical energy by using uninterrupted flow of water in motion to turn a Turbine connected to an electric generator [6].

(ii) The amount of electricity that can be produced by hydro-electricity generating system depends on the plant efficiency, volumetric water flow through the turbine, and the head of the water from the water surface to the turbine [8].

The total power output $P$, that can be generated from water in hydroelectric power plant is directly proportional to the height $h$ of water from the inflow to the turbine and the rate, $r$ of flow of water. Thus:

$$
\begin{gathered}
P \propto r h \\
\therefore P=g r h
\end{gathered}
$$

Where $g$ is the acceleration due to gravity (usually, $g=$ $9.81 \mathrm{~m}^{2} \mathrm{~s}^{-1}$ )

If the head of water translates to release, then higher volume of water in the reservoir will translate to higher quantity of electricity produced by the hydroelectric power (HEP) plant, $[9,10]$. To maximize HEP therefore the head of water (HoW) in the reservoir must be adequately high such that the difference between the HoW and the turbine must be at premium so that the kinetic energy produced by the mass of water will be adequate to produce the require torque that will generate expected power output. The maximum height of water is fixed by natural factors like the height of river bed, the amount of water involved and other environmental factors. The location of the power generation unit can be adjusted based on the maximum total power output that would be generated. Usually the power generation unit is located at levels lower than ground level so as to get the maximum head of water. The total flow rate of water can be adjusted through the penstock based on the design requirements [11].

\subsection{The Pumped Storage Phenomenon}

About 300 pumped storage projects are in operation all over the world, with a total installed capacity of 83,000 MW. Currently, several tens of similar projects are under construction. It stores excess electricity generated during times of low demand (such as night periods) and plunges it back to the system by pumping back the used volume to 
attain fresh water head which is in turn used to turn the turbine when demand is high, and, it is friendly to the environment, with no emissions of pollutant [12].

One instrument which is commonly used to provide affordable electricity with the right quality is PumpedStorage. It is as an excellent tool for managing electricity generating systems. Its dynamic features adds to the quality of the network, It functions as a voltage and frequency regulator, it provides immediate response for load following, it is a source of cheap electricity, it is available whenever needed and in cases of emergency. The quality of electricity produced with attendant and economic gains are considered added advantage over and above other electricity generating systems especially in competitive markets. The unique characteristics of Pumped-Storage made it viable in most developed and developing countries $[1,13]$.

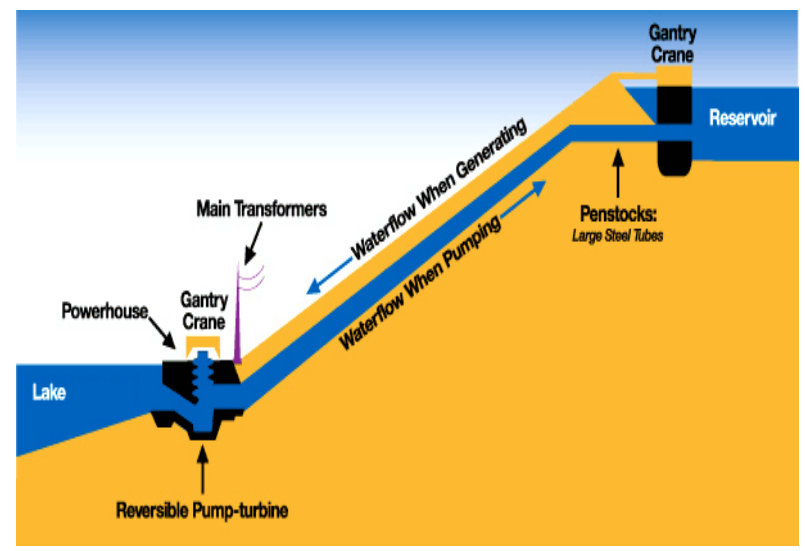

Source: Ulowa Wiki

Fig. 1 : Schematic of pumped storage power plant

Table 1: Summary of efficiency of various pumps

\begin{tabular}{cc}
\hline \multicolumn{2}{c}{ Impulse turbines } \\
\hline Prime Mover & Efficiency Range \\
\hline Pelton & $80-90 \%$ \\
Turgo & $80-95 \%$ \\
Cross-flow & $65-85 \%$ \\
\hline \multicolumn{2}{c}{ Reaction turbines } \\
\hline Prime Mover & Efficiency Range \\
\hline Francis & $80-90 \%$ \\
Pump-as-turbine & $60-90 \%$ \\
Propeller & $80-95 \%$ \\
Kaplan & $80-90 \%$ \\
\hline Prime Mover & \\
\hline Undershot & Efficiency Range \\
Breastshot & $25-45 \%$ \\
Overshot & $35-65 \%$ \\
\hline
\end{tabular}

Pumped storage hydroelectricity option is a method of producing electricity stored for supply when demand is at its peak [14]. At times of low demand for electricity, excess electrical energy generated is used to pump water into an elevated reservoir for usage during peak period when the stored water is released back into the lower reservoir via a turbine, thereby generating more hydroelectricity. About $70 \%$ of the additional electrical energy is thus generated over and above the capacity of the original energy produced by the same volume of water where conventional hydroelectric system is used as currently done in Shiroro dam [15]. To cut cost, some utilities use abandoned mines site as the lower reservoir. Many other utilities use the natural height difference between two natural bodies of water such as expanded lake or artificial reservoirs, [16].

Pumped storage hydro-electricity works on a very simple principle. Two reservoirs at different altitudes are required (one above the turbine the other below it). When the water is released, from the upper reservoir, energy is created by the down flow which is directed through high-pressure shafts, linked to turbines. In turn, the turbines power the generators to create electricity. The pumping occurs during off-peak hours of the demand cycle, meaning that the plant can use inexpensive surplus power to pump water and then reclaim the stored energy to match higher demand during peak periods. To achieve this feat, water is pumped back to the upper reservoir by linking a pump shaft to the turbine shaft using a motor to drive the pump. The pump motors are powered from the energy generated by the hydroelectric system. However, the gains of the process can be obtained from the efficacy and the efficiency derivable from the recurrent process. A dynamic response involving generating units of the system can achieve maximum output, usually, within 16 seconds of their operation. Pump storage generation offers a critical back-up facility during periods of excessive demand on the national grid system.

In recent time, research efforts have been directed towards the development of reverse-engineered conventional pumps that can be used as hydraulic turbines. A centrifugal pump operates like a water turbine when it is run in reverse order. Because the pumps are mass-produced, they are more readily available and less expensive than turbines. It is estimated that the cost of a pump-as-turbine (PAT) is at least 50 percent less or even lower than that of a comparable turbine. However, for adequate performance, a micro-hydropower site must have a fairly constant head and flow because PATs have very poor partial-flow efficiency. It is possible to obtain full efficiency from PATs by installing multiple units, where 
they can be turned on or off depending on the availability of water in the stream. PATs are most efficient in the range of 13 to $75 \mathrm{~m}$ ( 40 to $250 \mathrm{ft}$.) of gross head. The higher the head, the less expensive the cost per kilowatt; this is generally the case with all turbines [17].

The difference between the level of the upper and lower reservoir is the head, for very high head it is necessary to use multistage pumps. However, for large installations with one stage pumps, a head in the range of between 300 and $600 \mathrm{~m}$ is required. For instance, 4 million cubic meter reservoir capacity is required to produce $1000 \mathrm{MW}$ in four hours at $400 \mathrm{~m}$ head. Seasonal storage reservoirs may require a capacity larger than one billion cubic meters to sustain pumped storage that will last the season. A pumped storage station costs in excess of US $\$ 2500 / \mathrm{kW}$ and the overall losses are about $25 \%$. Most pumped storage stations store sufficient water for 6-10 hours of operation [18].

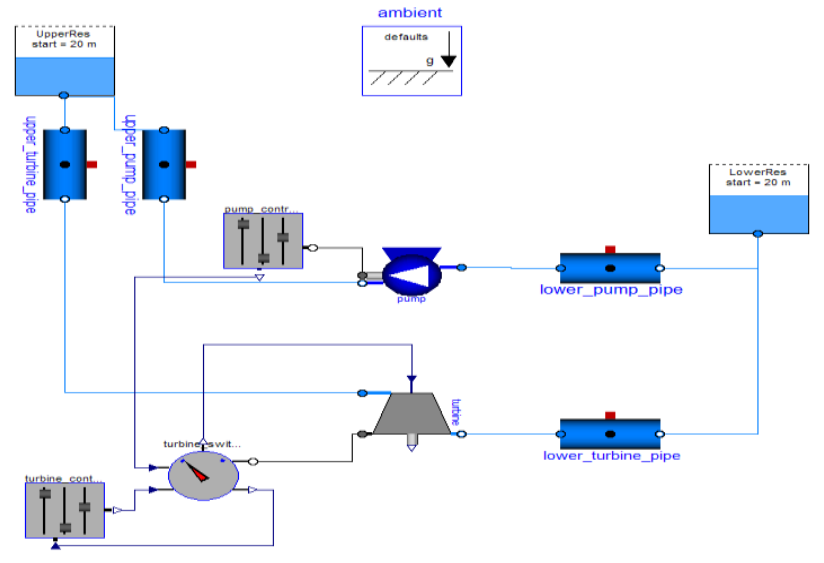

Source: System model [1]

Figure 2: Overall pumped-storage system model

Table 2: Global pumped-storage plants statistics [1]

\begin{tabular}{|c|c|c|}
\hline Country & Description of Facility & $\begin{array}{l}\text { Capacity } \\
\text { Installed } \\
\text { MW }\end{array}$ \\
\hline \multirow{2}{*}{ China } & $\begin{array}{l}\text { Guangzhou pumped storage } \\
\text { power station, Hong-Kong }\end{array}$ & 2,400 \\
\hline & $\begin{array}{l}\text { Tienhuangping Pumped Storage } \\
\text { Project }\end{array}$ & 1,800 \\
\hline \multirow{2}{*}{$\begin{array}{l}\text { United } \\
\text { Kingdom }\end{array}$} & Dinorwig, Wales & 1320 \\
\hline & $\begin{array}{l}\text { Ffestiniog Pumped Storage Plant, } \\
\text { Wales }\end{array}$ & 360 \\
\hline \multirow{4}{*}{$\begin{array}{l}\text { United } \\
\text { States }\end{array}$} & Ludington Pumped Water Plant & 1872 \\
\hline & Mt. Hope Pumped Water Plant, & 2,000 \\
\hline & Mount Elbert & 200 \\
\hline & Summit Pumped Water Plant, & 1500 \\
\hline \multirow{2}{*}{ Others } & $\begin{array}{l}\text { Rance River, St. Malo France } \\
\text { hybrid pumped water-tidal } \\
\text { plant }\end{array}$ & 240 \\
\hline & $\begin{array}{lr}\text { Drakensberg } & \text { Pumped } \\
\text { Storage Scheme, } & \text { South } \\
\text { Africa }\end{array}$ & 1,000 \\
\hline
\end{tabular}

Table 3: Inflow, release and power generated between 1990 and 2004

\begin{tabular}{rrcc}
\hline YEAR & \multicolumn{1}{c}{ INFLOW } & PGN(MW)X10^3 & \multicolumn{1}{l}{ RELEASE } \\
\hline 2004 & 72929.1 & 242.5629 & 115879.2 \\
2003 & 103025.7 & 253.8834 & 116120.9 \\
2002 & 82580.84 & 218.8941 & 101550.9 \\
2001 & 84914.1 & 267.5201 & 122366.5 \\
2000 & 77394.03 & 257.1351 & 102406.1 \\
1999 & 93149.9 & 209.7861 & 105938.4 \\
1998 & 81361.84 & 214.1446 & 107417.4 \\
1997 & 83817.42 & 223.0044 & 103589.6 \\
1996 & 77454 & 201.9469 & 95395.35 \\
1995 & 55352.16 & 194.4828 & 90808.48 \\
1994 & 81935.19 & 204.794 & 96428.16 \\
1993 & 73861.74 & 211.9957 & 97810.77 \\
1992 & 80755.34 & 230.0002 & 108718.6 \\
1991 & 73541.35 & 199.7155 & 90598.74 \\
1990 & 73343.42 & 215.26887 & 97404.26 \\
\hline
\end{tabular}

And the advantages include:

- Increase in profitability for plant owners in volatile electricity spot markets

- Allowance of optimization of global operations of power plant fleets and electrical network infrastructures

- Has higher global cycle efficiency compared to other large storage solutions (approximately 80\%)

- Has a positive environmental impact by enabling increased use of renewable energy sources [18].

The statistics of pumped storage plants worldwide is as summarized in Table 2 below:

The basic equation that relates release with energy produced in a hydroelectric system is given by [19]:

$$
k W H_{t}=2725 R_{t} H_{t} n
$$

where $R_{t}$ is the release into the penstock in $\mathrm{Mm}^{3}, H_{t}$ is head in meters and $n$ is efficiency.

A biometric analysis of the data supplied by Shiroro dam management for average turbine flow and inflow revealed incoherent correlation which failed to make a categorical statement about the truth of its empiricism and therefore cannot be applied in any serious scientific research work upon which the fate of such an important magnitude as the power generation project could be based. We have randomly selected July 23 of each year under consideration. Table 3 revealed a major anomaly in the structure of the data selected through stochastic process from the pool of the aforementioned data. A close study shows that in 2003 for instance release is greater than inflow. The chart in Figure 6 presents a more expository revelation of our claim.

Based on these observations it is obvious that the data provided in Shiroro dam cannot be relied upon, hence the need for simulation of data. Equation (11) to (19) was solved through the software named TORA, eight 
iterations were performed. The storage $k$ of the reservoir is being varied and the result is as tabulated in Table 3 .

\section{METHODOLOGY}

Reservoir operation is an important element in water resources planning and management. It consists of several control variables that defines the operation strategies for guiding a sequence of release to meet specific demands of the stakeholders with different objectives, such as flood control, hydropower generation and allocation of water to different users. A major difficulty in the operation of reservoirs is the fluctuation in storage. Therefore, it is necessary to optimize reservoir operation in determining adequate water storage for generation of hydropower [19 - 21]. Of concern in this work is the uninterruptable supply of water resources into the reservoir to ensure adequate supply of water for the purpose of generating electricity from a hydroelectric system all year round, especially during drought and dry season. To this end, pumped storage may be introduced in the hydropower plant to facilitate an efficient recycling of the available water resources at these periods of the year. According to the U.S department of the Interior Bureau of Reclamation Power Resources Office, July 2005, demand for electrical power supply varies greatly during the day and night. These demands vary considerably from season to season. In order to maximize storage so as to ensure constant electrical power supply, it is necessary to find a way of recycling the water used to turn the turbine [22]. Hence a pumped storage, the basic principle of the pumped storage goes thus, the release from the reservoir is pumped to a storage tank where it can be used to return the turbine during the period of drought, thus ensuring constant supply of electricity the year round. Optimization models are based on clearly defined goals (objective functions), criteria for evaluation of control decisions, and constraints as limitations during optimization [23 - 26]. In our own case, it is enough to maximize storage so that the Shiroro Hydroelectric power plant will have adequate water supply the year round. The typical constraints in a reservoir optimization model, including conservation of mass and other hydrological and hydraulic constraints, minimum and maximum storage and release, hydropower and water requirements as well as hydropower generation limitations, are presented as follows:

- Hydraulic constraints are defined by the reservoir continuity equation.

$$
\begin{gathered}
S(t+1)=S(t)+1(t)-R(t)-E(t) \forall t \\
=1,2, \ldots, T
\end{gathered}
$$

Where $S(t+1)$ is storage at time step $t+1 ; S(t)$ is storage at time step $t, 1(t)$ is the reservoir net inflow at time step $t$ (including reservoir inflow, precipitation and evaporation); $R(t)$ is the reservoir outflow at time step $t$ $E(t)$ is the evaporation loss at time step $t$ corresponding to the water spread area at the average storage $[S(t)+S(t+1)] / 2 . T$ is the total number of time steps in the period under consideration.

- Constraints on discharge defined by maximum and minimum permissible reservoir releases:

$$
S_{\min } \leq S(t) \leq S_{\max } \quad \forall \quad t
$$$$
=1,2, \ldots, n
$$

- Constraints on storages defined by maximum and minimum permissible reservoir storages:

$$
\begin{gathered}
R_{\min } \leq R(t) \leq R_{\max } \quad \forall \quad t \\
=1,2, \ldots, n
\end{gathered}
$$

- Constraints on elevations defined by maximum and minimum permissible level at specified sites:

$$
h_{\min } \leq h(t) \leq h_{\max } \quad \forall \quad t=1,2, \ldots, n
$$

- Constraints on hydropower generations defined by maximum capacity and minimum requirement of hydroelectricity:

$$
H_{\min } \leq H(t) \leq H_{\max } \quad \forall \quad t=1,2, \ldots, n
$$

$H P(t)$ is a nonlinear function of $S(t)$ and $R(t)$.

- Energy production, expressed as the energy production capacity (EPC):

$E P C=C^{*} \leq R E Q(t)^{*} H(t)^{*} \eta \quad \forall t=1,2, \ldots, n^{o}$

Where $C$ is the conversion factor for potential to electrical energy, $H$ is the average head over turbine and $\eta$ is the energy plant efficiency.

- The energy that can be produced is restricted by the plant capacity (PCAP) and number of hours available for energy production (NHP). Thus, the maximum peak energy produced (MPEP) is:

$\operatorname{MPEP}(t)=\operatorname{PCAP}(t){ }^{*} \eta^{*} N H P(t) \quad \forall t=1,2, \ldots, n$ (10) The energy produced at any time $t$ is:

$P K E(t)=\min (T E P(t), \operatorname{MPEP}(t)) \forall t=1,2, \ldots, n(11)$ Where $P K E$ is the peak energy produced and TEP is the total energy that can be produced at a particular time. One of the problems associated with the operation of the reservoir is the operational and release policy adopted. At Shiroro reservoir, annual flooding of lower Niger plains occurs when the spillways are opened in September during high inflows. While during the period of low inflows (March to May), head of water in the reservoir is often below the desired level. Operation of reservoirs is based on experience of the water managers. A viable resolution of these anomalies may therewith be found with the proposed optimization technique which employs the recycling of released $R_{t}$ as the inflow of the reservoir [10]. 


\subsection{Optimizing the Reservoir's Operation}

From literature, the energy production capacity (EPC) is more than often, a function of storage [27 - 29]. However storage at time $t$ is determined by the inflow of water and the storage at time $(t-1)$ when a discretized variable is used. It therefore follows that the EPC can be wholly determined by the storage of the reservoir. Hence, to maximize EPC output is tantamount to maximizing storage. The objective function for the reservoir optimization process is simplified thus:

$$
\text { Maximize } \sum_{t=1}^{T}[S(t)+I(t)]
$$

Subject to:

$$
\begin{aligned}
& S(t+1)-S(t)-I(t)-R(t)-l(t)=0 \\
& R(t)-l(t) \leq 0 \\
& S(t+1) \leq k \\
& I(t)+0.7 R(t) \leq K \\
& I(t)+0.7 R(t) \leq K \\
& l(t)+0.3 R(t) \leq 0 \\
& R(t) \leq K \\
& I(t) \geq 0, R(t) \geq 0, S(t) \geq 0, l(t) \geq 0 \\
& S_{\min } \leq S_{\max } \leq K \\
& \quad \forall \quad t=1,2, \ldots, n
\end{aligned}
$$

Where, $S_{t+1}$ is the final storage at time $t, S_{t}$ is the storage at the beginning of the period $t, K$ is the storage capacity of the reservoir; $R_{t}$ is the release at time $t, l_{t}$ is the total loss at time $\mathrm{t}$ while $I_{t}$ is the inflow at time t. Equation (12) is the reservoir continuity equation, while equation (13) is implemented to account for the recycling of the release used to turn the turbine.

\subsection{Reservoir's Inflow and Release Statistics}

This section provides the summary of the statistics obtained from the various analyses made using the approach adopted in the preceding chapter. Table 4 is a collection of the statistical parameters used as decision variables for our analyses. The figure below shows the graph of inflow and release from the reservoir against years under consideration, from the graph, it can be perceived that from January to May of these years the release is comparatively greater than inflow while from June to August of the same period the inflow is appreciably greater than the release. This shows that an extra storage must be somewhere around the downstream to make-up for the shortfalls in the release from January to May to optimize the hydroelectric power generated for these months. To this end, a pumped storage becomes a viable solution to the irregularity observed in the data. Despite many devoted effort to correctly forecast rainfall and run off, rainfall prediction still remain problematic. Rain is a form of precipitation. It is the water that falls from the cloud to the Ground through hydrological cycle. The radius of rain is of a drop is slightly greater than $250 \mu \mathrm{m}$.

The pattern and invariably the amount of rainfall are among the most important factors that affect the output of hydroelectric power generating systems [30]. Statistical observations obtained from pattern of these systems are precipitation dependent. Rainfall are essential and are indeed fundamental to understanding the rainfall runoff process; therefore the accuracy of the rainfall data at some critical point is very important and

\begin{tabular}{|c|c|c|c|c|c|}
\hline & CORREL & COVAR & SLOPE & MEAN & STDV \\
\hline $\begin{array}{l}\text { RELEASE } \\
(1990-2007)\end{array}$ & & & & 101671.3 & 13532.51 \\
\hline $\begin{array}{c}\text { INFLOW } \\
(1990-2007)\end{array}$ & 0.6929 & 105796009 & 0.7851 & 78775.43 & 11945.15 \\
\hline
\end{tabular}
significant to any specific use a set of data is applicable to. Subsequent paragraphs enumerate the import of main results of the evolving analysis of the record of rainfall at Shiroro hydropower stations during the period under consideration.

Table 4: Records of pattern of rainfall into Shiroro dam between 1990 and 2008

\begin{tabular}{lllll}
\hline YEAR & MEAN $(\mathrm{mm})$ & MEDIAN & STDV & MAX \\
\hline 2008 & 88.2 & 28.9 & 115.5663 & 305.7 \\
2007 & 119.916667 & 83.55 & 126.3198 & 332.3 \\
2006 & 128.075 & 78 & 150.0853 & 425 \\
2005 & 92.2083333 & 64.15 & 103.347 & 247.1 \\
2004 & 85.025 & 44.45 & 96.8482 & 236.4 \\
2003 & 110.058333 & 88.35 & 120.0423 & 351.5 \\
2002 & 97.325 & 77 & 106.2391 & 286.6 \\
2001 & 112.116667 & 78.85 & 128.6778 & 360 \\
2000 & 102.625 & 95.2 & 114.6116 & 364.7 \\
1999 & 113.1 & 73.5 & 131.1867 & 410.7 \\
1998 & 104.591667 & 86 & 110.0194 & 280.8 \\
1997 & 143.425 & 122 & 152.9154 & 473.2 \\
1996 & 103.575 & 66.25 & 112.3733 & 307.2 \\
1995 & 100.35 & 54.85 & 133.3404 & 443.8 \\
1994 & 98.125 & 66.6 & 107.1328 & 264.7 \\
1993 & 114.533333 & 50 & 138.5029 & 377.7 \\
1992 & 120.2 & 107 & 125.7707 & 368.1 \\
1991 & 113.191667 & 29.95 & 148.9809 & 450.3 \\
1990 & 145.775 & 151.9 & 149.3903 & 416.1 \\
\hline & & & &
\end{tabular}

Table 5: Inflow/Release for Shiroro power project SUMMARY STATISTIC

The onus here is:

a. To analyze a record of rainfall for the purpose of establishing trends or pattern of changes observed. 
b. To demonstrate the direct method of analyzing rainfall data that can be used for purpose of planning future power generation output.

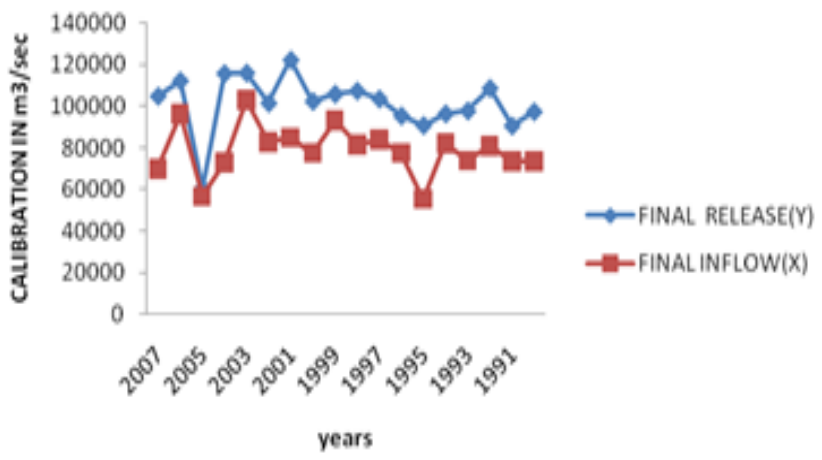

Figure 3: inflow versus release from the reservoir for 1991-2007

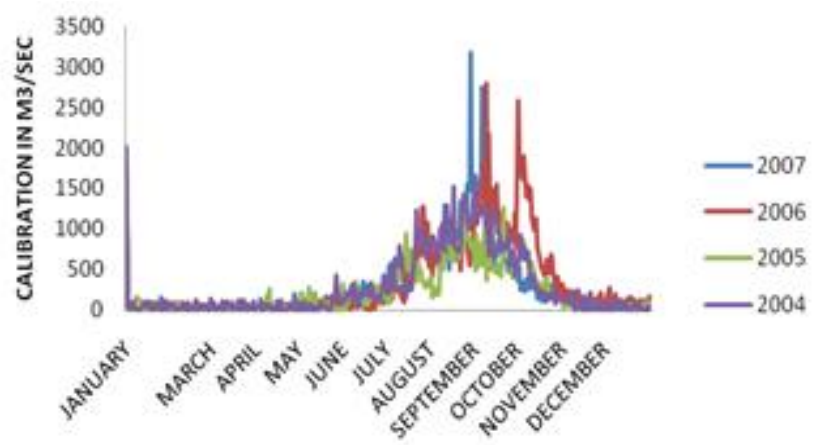

Figure 4: daily inflow into the reservoir for the years 2004 to 2007

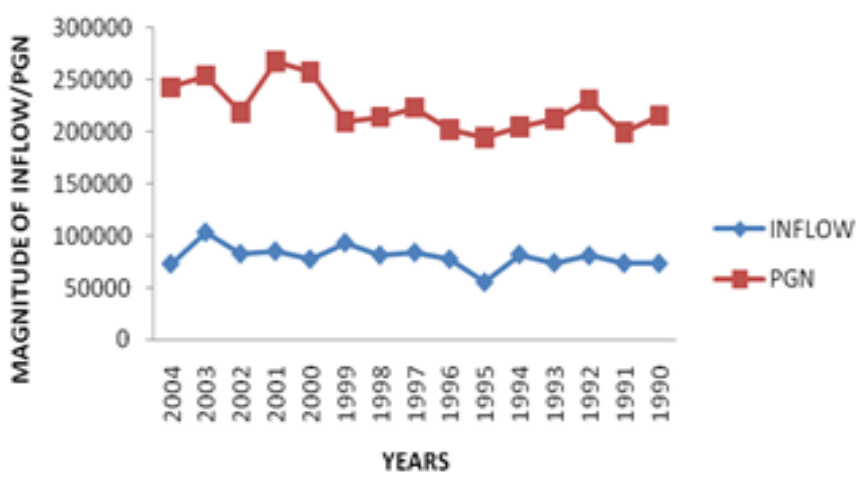

Figure 5: Relating inflow with power generated at Shiroro dam for the period 1990 - 2004

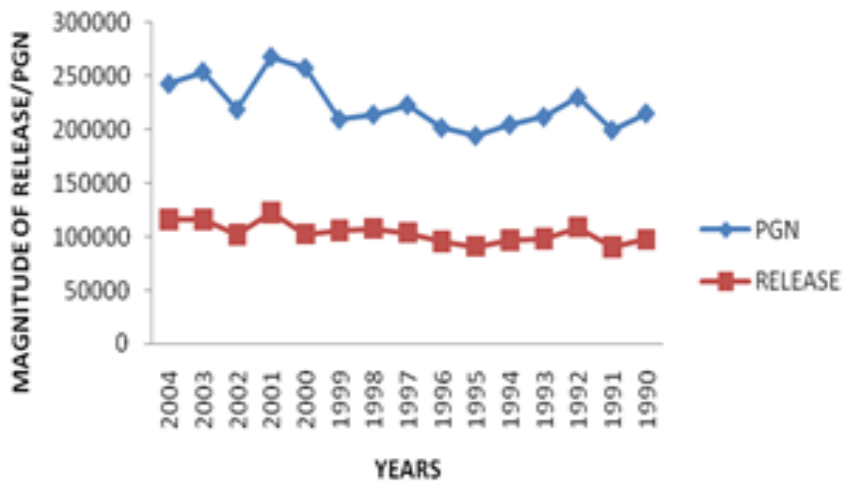

Figure 6: Release versus power generated for the period $1990-2004$
In this paper, Microsoft excel software statistical package is used to analyze the Rainfall regime. The average annual rainfall in respect of Shiroro power project is 1325213 $\mathrm{mm}$ with the highest rainfall record of $1749.3 \mathrm{~mm}$ in 1990 while the lowest record of $617.4 \mathrm{~mm}$ was observed in 2008. The statistical measures of taken mean maximum, minimum, the standard deviation and coefficient of variation of the annual rainfall for the station is shown in Table 4 while the summary of the statistics are presented in Table 5 .

\section{RESULTS AND DISCUSSION}

Reservoir inflow observation is one of the most reliable methods of estimating the runoff yield. Understanding reservoir flow pattern is therefore fundamental to achieving outstanding success during the process of monitoring of water budget in a reservoir [31,32]. We are required to know the lowest dependable flow on one hand and the highest flood level possible in the river on the other hand. The former is useful in the design of various components for proper optimization of water resources while the latter provides information of flooding which the structure will have to curtail [33]. The flow rate of a river usually refers to the volume of water that passes through a section of the river in a unit time in $\mathrm{m}^{3} / \mathrm{sec}$. [34]. The average annual turbine discharge by analysis at Shiroro is $9303.4 \mathrm{~m}^{3} / \mathrm{sec}$ between 1990 and 2004, with Maximum turbine discharge of $12412 \mathrm{~m}^{3} / \mathrm{sec}$ occurring in 2001 . Figure 3 below shows the relationship between the inflow and the release from the reservoir for the years under consideration. The graph showing daily variation of reservoir inflow for the years under consideration is described by Figure 4.

A verification of the relevance of inflow information to the development of a viable model for optimization process for hydropower system is presented in Figure 5 while Figure 6 is a directimplication of Figure 8 since ideally release is proportional to inflow into the reservoir $[1,35]$.

The Biometric analysis of the inflow/release relationship in the case of Shiroro hydropower project can be summarized by observing a linear relationship using regression analysis. This is presented in Figure 7. The regression analysis for the inflow and release of the reservoir was carried out using MS-Excel graphics. The release when there is no inflow as predicted by the regression line $y=A+B x$ is 16583 while the rate of change of release with respect to inflow (slope) is 0.6117 . Thus the equation $y=0.6117 x+16583$ as 
shown in the graph describes the variation of annual reservoir inflow for various years.

Figure 8 above depicts the relationship between the optimized result and the storage in the reservoir at any time $t$ and it can be inferred from the graph that there is a perfect correlation between $\mathrm{z}$ and $\mathrm{k}$, that is for every increase in storage value there is a corresponding increase in the optimized result which shows that the linear program employed in the solution is consistent with the result of our analysis. It also agrees with existing literature $[33,34]$.

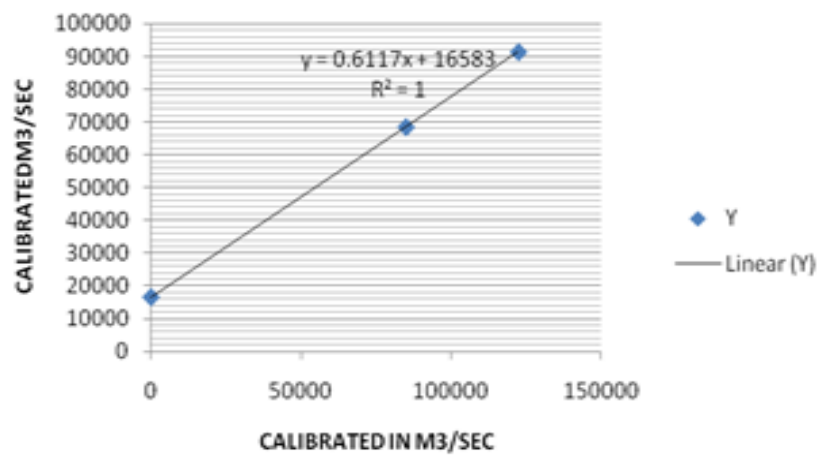

Figure 7: Regression line of inflow and release of the reservoir

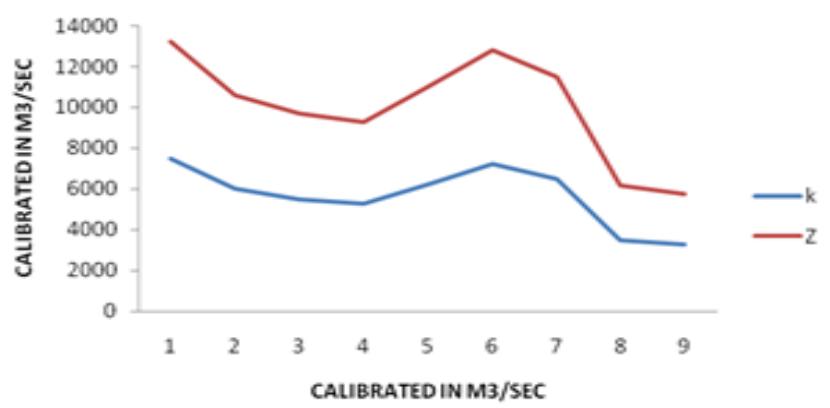

Figure 8: Optimized result $z$ versus storage $k$ in the reservoir

\section{CONCLUSION}

In the paper, we have proposed a new but simplified method for improving the efficiency and by implication, the production output of hydroelectric power generation at Shiroro dam especially during the period of drought. This work employs optimization models to explore viable engineering solution options thereby enriching the literature with the ultimate goal of arresting the tetraheaded monster that is responsible for the incessant power failure that has plagued the life of an average Nigerian for decades now. And it is our belief that our proposed model will curb all the economic discomfort and colossal waste currently incurred both by the citizenry and government due to the inadequacies of the power sector of the economy. It will also lead to improved technological advancement if properly

harnessed in order that our collective efforts towards achieving the vision 20:2020 may come to fruition.

\section{REFERENCES}

[1] Ajibola, 0. O. E., Ajala, O. S., Akanmu, J. O., Balogun, O. J. "Optimizing Hydroelectric Power Generation: The Case of Shiroro Dam". Proceedings of the World Congress on Engineering 2017, Vol I WCE 2017, July 5-7, 2017, London, U.K. 2017.

[2] Perlman, H. "Hydroelectric power: how it works". http://ga.water.usage.gov/edu/hyhowworks.html 2010.

[3] Madsen, H. "Parameter estimation in distributed hydrological catchment modelling using automatic calibration with multiple objectives". Advances in Water Resources. Vol. 26, Number 2, pp. 205-216. 2003.

[4] Karamouz, M., Sziarovsky, F., Zahraie, B. "Resources system analysis". Lewis Publisher. Washington, D.C., pp. 441-484. 2003.

[5] Rosenthal, R. E."A Nonlinear Network Flow Algorithm for Maximization of Benefits in a hydroelectric Power system". Operational Research, Vol. 29, Number 4, pp 763-786. 1981.

[6] Revelle, C. "Optimizing reservoir resources: including a new model for reservoir reliability". John Wiley \& Sons, Inc. pp 45-64. 1999.

[7] Forrester, J. W. "Some basic concepts in system dynamics. Sloan School of Management", Massachusetts Institute of Technology. UK. 2009.

[8] Mays, L. W., Tung, Y. K. "Hydrosystems Engineering and Management". McGraw-Hill Water Resources and Environmental Engineering Series. USA. 2014.

[9] US Power Resources Office. "Hydroelectric power: managing water in the west". Bureau of Reclamation, Power Resources Office, US Department of the Interior. USA. 2005.

[10] Phach, N. V. "Basis of science for improving efficiency of the integrated exploitation HoaBinh hydropower work". State level scientific research project, Electricity of Vietnam, (in Vietnamese). 1994.

[11] Vedula .S., Mujumdar P. P. "Modelling techniques and analysis". Tata McGraw-Hill Publishing Company limited. New Delhi. 2005.

[12] Yeh,W.L Becker, and W. Chu. "Real-time hourly reservoir operation". Journal of water Resources Planning and Management, Vol. 105(WR2), pp. 187 - 203. 1979.

[13] Jha, A.K., Bloch, R., Lamond. "Cities and flooding: a guide to integrated urban flood risk management for the $21^{\text {st }}$ century". The World Bank, Washington. 2012.

Vol. 37, No. 1, January 2018 
[14] Pereira, M. V. F., Pinto, L. "Stochastic Optimization of a Multireservoir Hydroelectric System - a Decomposition Approach". Water Resources Research. Vol. 21, Number 6: 779-792. 1985.

[15] Akanmu, J. 0. "Model for the optimal operation of shiroro reservoir". PhD Dissertation. Department of civil and environmental engineering, university of Lagos, Akoka. Nigeria. 2007.

[16] Yang, X., Parent, E., Claude, M., Roche, P.-A. "Comparison of real-time reservoir-operation techniques". Journal of Water Resources Planning and Management121(5): 345-351. 1995.

[17] Yapo, P. O., Gupta, H. V., Sorooshian, S. "Multiobjective global optimization for hydrologic models". Journal of Hydrology. Vol., pp. 83-97. 1998.

[18] Fodstad, L. A. Pumped storage. Risoe.dtu.dk/en/.../ storage/lars_fodstad_ tilladelsa.ashx. 2009.

[19] Karaagac U, J. Mahseredjian, S. Dennetière. "Modelling and Simulation of the Start-up of a Pumped Storage Power Plant Unit, International Conference on Power Systems Transients. Kyoto. Japan. 1998.

[20] Adegbehin, A.B., Yusuf, Y.O., Iguisi, E.O., ZubairuJimoh O. D. "Reservoir inflow pattern and its effects on hydroelectric power generation at the Kainji Dam, Niger State, Nigeria". WIT Transactions on Ecology and the Environment, Vol. 203, pp. 233 244. 2016,

[21] Duranyildiz, I., Onoz B., Bayazit M. "A ChanceConstrained LP Model for Short term reservoir Operation Optimisation".Turkish Journal of Engineering and Environmental Science. Vol.23, pp. 181-186. 1999.

[22] Labadie, J. "Optimal operation of multireservoir systems: state-of-the-art review". Journal of Water Resources Planning and Management (C) ASCE pp. 111. 2004

[23] Akter, T., Simonovic, S. P. "Modelling uncertainties in short-term reservoir operation using fuzzy sets and a genetic algorithm". Hydrological Science Journal, Vol. 49, Number 6, pp. 1081-1079. 2004.

[24] Chen, L. "Real time genetic algorithm optimization of long term reservoir operation". Journal of the American Water Resources Association. Vol.39, Number 5, pp. 1157-1165. 2003.

[25] Kelman, J., Stedinger, J., Cooper, L. A., Hsu, E. "Sampling stochastic dynamic programming applied to reservoir operation". Water Resources Research. Vol. 26, Number 3, pp. 447-454. 1990,
[26] Yeh, W. "Reservoir management and operations models: A state-of-the-art review". Water Resources Research. Vol.21, Number 12, pp. 1797-1818. 1985.

[27] Chan-Ki Kim, Vijay K. Sood, Gil-Soo Jang, SeongJoo Lim, Seok-Jin Lee. "HVDC Transmission: Power Conversion Applications in Power Systems". John Wiley and Sons (Asia) Pte Ltd. Singapore. 2009.

[28] Adegbehin, A. B. Effects of some weather parameters and reservoir inflow pattern on hydroelectric power generation in Kainji dam Niger state, Nigeria. M.Sc. Dissertation.Ahmadu Bello University, Zaria, Nigeria. 2016.

[29] Abdulkadir, T. S., Salami, A. W., Sule, B. F., Adeyemo, J. A. "Neural Network Based Model for Forecasting Reservoir Storage for Hydropower Dam Operation". International Journal of Engineering Research and General Science. Vol. 3, Issue 5, pp.639 - 647. 2015.

[30] Oliveira, R. and Loucks, D. P. "Operating rules for multireservoir systems". Water Resources Research 33(4): 839-852. 1997.

[31] Nwobi-Okoye, C. C. and Igboanugo, A. C. "Predicting water levels at Kainji Dam using artificial neural networks", Nigerian Journal of Technology, Vo. 32 (1), pp. 129 - 136, 2013

[32] Salami, A. W., Mohammed A. A., Adeyemo, J. A. and Olanlokun, O. K. "Modeling of reservoir inflow for hydropower dams using artificial neural networks", Nigerian Journal of Technology, Vol. 34 (1), pp. $28-36,2015$.

[33] John, L. "Optimal operation of multireservoir system: State-of-the-Art review". Water Resources Planning and Management. Vol.130, Number 2, pp. 93-111. 2004.

[34] Loucks D. P., Stedinger, J. R., Shamir, U. "Modelling Water Resources Systems: issues and experience". Civil Engineering System. Vol. 2, pp 1-9. 1985.

[35] Otun, J. A., Onemano, J. I. and Alayande A. W. "Assessment of hydropower potentials of Kangimi reservoir in Kaduna State, Nigeria", Nigerian Journal of Technology, Vol. 31 (3), pp. 300 - 307, 2012.

[36] Nandalal. K. D. W., Bogardi, J. J. "Dynamic programming based on operation of reservoirs: applicability and limits". Cambridge University Press, UK, 2007.

[37] Ngo, L. L. "Optimising reservoir operation: A case study of the HoaBinh reservoir, Vietnam". Ph.D. Thesis. Institute of Environment \& Resources. Technical University of Denmark, Denmark. 2006. 